\title{
Extreme climate, not extreme weather: the summer of 1816 in Geneva, Switzerland
}

\author{
R. Auchmann ${ }^{1}$, S. Brönnimann ${ }^{1}$, L. Breda ${ }^{2}$, M. Bühler ${ }^{1}$, R. Spadin ${ }^{2}$, and A. Stickler ${ }^{1}$ \\ ${ }^{1}$ Oeschger Center and Institute of Geography, University of Bern, Bern, Switzerland \\ ${ }^{2}$ Institute for Atmospheric and Climate Science, ETH Zürich, Zürich, Switzerland \\ Correspondence to: R. Auchmann (renate.auchmann@giub.unibe.ch)
}

Received: 3 October 2011 - Published in Clim. Past Discuss.: 8 November 2011

Revised: 18 January 2012 - Accepted: 20 January 2012 - Published: 24 February 2012

\begin{abstract}
We analyze weather and climate during the "Year without Summer" 1816 using sub-daily data from Geneva, Switzerland, representing one of the climatically most severely affected regions. The record includes twice daily measurements and observations of air temperature, pressure, cloud cover, wind speed, and wind direction as well as daily measurements of precipitation. Comparing 1816 to a contemporary reference period (1799-1821) reveals that the coldness of the summer of 1816 was most prominent in the afternoon, with a shift of the entire distribution function of temperature anomalies by $3-4{ }^{\circ} \mathrm{C}$. Early morning temperature anomalies show a smaller change for the mean, a significant decrease in the variability, and no changes in negative extremes. Analyzing cloudy and cloud-free conditions separately suggests that an increase in the number of cloudy days was to a significant extent responsible for these features. A daily weather type classification based on pressure, pressure tendency, and wind direction shows extremely anomalous frequencies in summer 1816, with only one day (compared to 20 in an average summer) classified as high-pressure situation but a tripling of low-pressure situations. The afternoon temperature anomalies expected from only a change in weather types was much stronger negative in summer 1816 than in any other year. For precipitation, our analysis shows that the $80 \%$ increase in summer precipitation compared to the reference period can be explained by $80 \%$ increase in the frequency of precipitation, while no change could be found neither in the average intensity of precipitation nor in the frequency distribution of extreme precipitation. In all, the analysis shows that the regional circulation and local cloud cover played a dominant role. It also shows that the summer of 1816 was an example of extreme climate, not extreme weather.
\end{abstract}

\section{Introduction}

One of the most severe climatic deviations of the past few hundred years in central Europe was the "Year Without Summer" (YWS) 1816 (Stothers, 1984; Briffa and Jones, 1992; Harington, 1992; Robock, 1994, 2000). This event has been studied extensively both by historians (Skeen, 1981; Pfister, 1992, 1999) and climate scientists (Briffa and Jones, 1992; Kington, 1992; Shindell et al., 2004) with respect to causes and consequences. The event is mostly related to the 1815 eruption of Tambora in Indonesia, which injected a huge amount of sulfur into the stratosphere that was capable of altering global climate (Stommel and Stommel, 1983; Stothers, 1984, 1999; Piervitali et al., 1997; Briffa et al., 1998; Chenoweth, 2001; Stendel et al., 2005). In addition, reduced solar activity related to the so-called Dalton minimum might have played a role (Lean et al., 1995; Mann et al., 1998).

The global scale cooling due to the Tambora eruption is estimated to approximately $0.5^{\circ} \mathrm{C}$. However, in Central Europe where consequences were devastating both economically and socially (Hoyt, 1958; Stothers, 1999; Oppenheimer, 2003), the cold anomalies were much larger (Trigo et al., 2009; Luterbacher et al., 2004), calling for additional or amplifying mechanisms.

Most previous studies on the YWS in Europe addressed the monthly or seasonal scale (e.g. Self et al., 1980; Trigo et al., 2009), for which abundant information is available from direct measurements as well as climate proxies and documentary data. Daily or even sub-daily data have much more rarely been studied (Baron, 1992; Chenoweth, 2009). This would be important, however, as sub-daily information might potentially give further insights into the underlying 

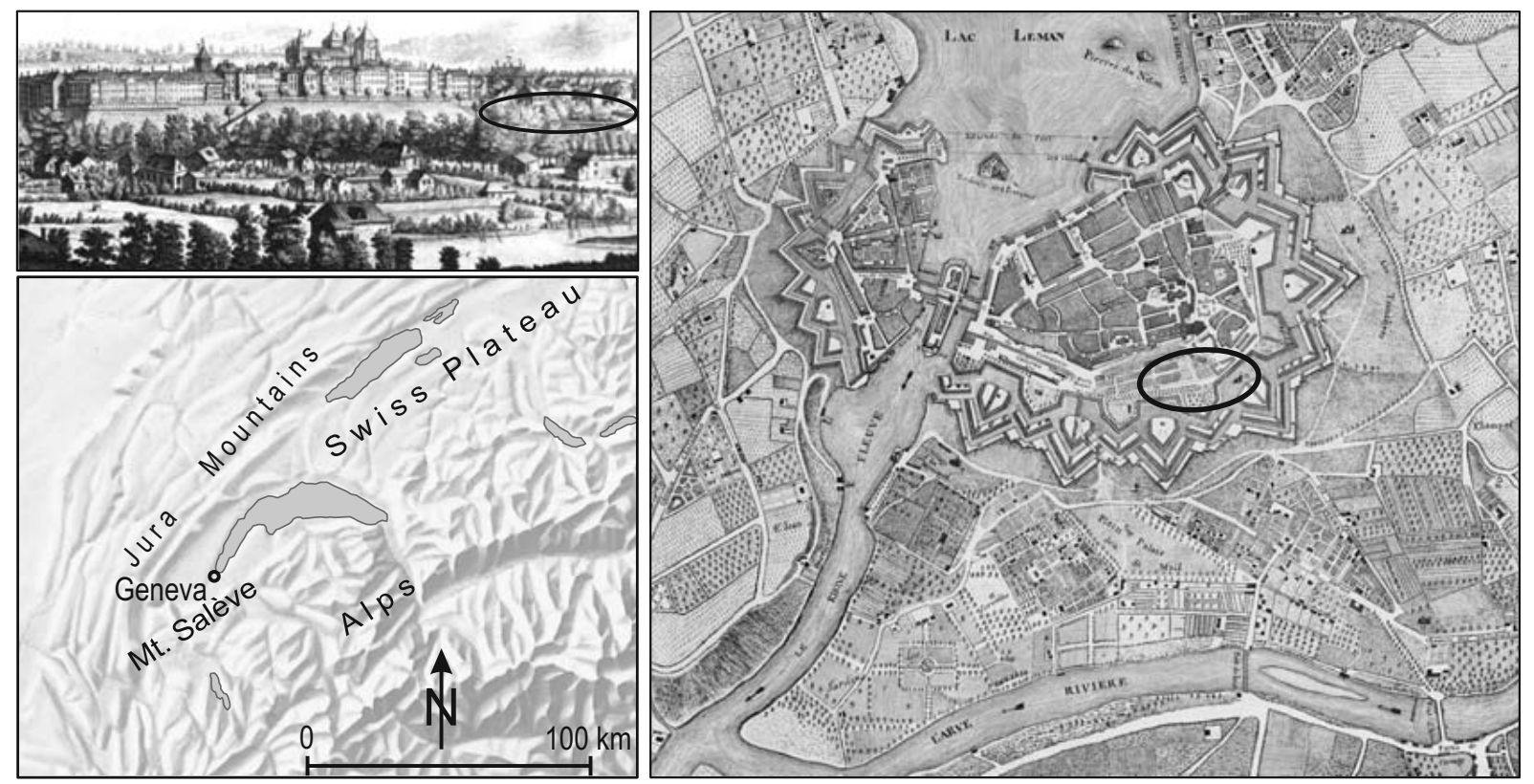

Fig. 1. Approximate location of the weather station of Geneva in 1799-1821 in a contemporary view (top left panel) and map (right panel) of the city. The bottom left panel shows the topography of the region (relief: Eidgenössische Erziehungsdirektorenkonferenz).

processes. For the assessment of changes in climate variability and extremes, daily to sub-daily data resolution is indispensable (Brandsma and Können, 2006; Alexander, 2006). In our study, temporal attribution of the summer 1816 cooling (e.g. morning or afternoon cooling) as well as the analysis of a combination of parameters (e.g. cloud cover and temperature) cannot be conducted by using mean data. In contrast to measured values (i.e. the sub-daily data used in this study), they do not represent a state of the atmosphere. Both methods may contribute to a better understanding of the structure of the cooling and provide some new details into processes and mechanisms involved. One main restriction so far was data availability as many data series were simply not available in their original form.

In this paper we analyze the YWS 1816 in a recently digitized record of twice daily measurements performed in Geneva, Switzerland, including air temperature, pressure, cloud cover, wind speed and direction, and daily precipitation. Geneva is in the region with the largest negative temperature anomaly (e.g. Pfister, 1992; Trigo et al., 2009) in summer 1816. The aim of the paper is to analyze to what extent the year without summer was characterized by extreme climate or by extreme weather (i.e. whether changes are largest in the central part of the frequency distribution or near the extremes). Furthermore, by analyzing sub-daily data we hope to get more insights into the mechanisms responsible for the YWS. Finally, the paper aims at identifying new characteristics of the YWS that are testable in or comparable to a modeling framework.
The paper is organized as follows. In Sect. 2, data (including all aspects of homogeneity) and methods are explained. In Sect. 3 we present and discuss the results. Conclusions are drawn in Sect. 4.

\section{Data and methods}

\subsection{Meteorological measurements and observations from Geneva}

The data from Geneva were digitized from printed sources (Journal de Genève, Bibliothèque britannique/universelle) reaching back to the $1780 \mathrm{~s}$. We digitized all elements (temperature, precipitation, pressure, clouds, wind) at the full temporal resolution and converted the data to current units. No further pressure reduction was necessary as it was already reduced to constant $10^{\circ} R$. This is different to today's standard $\left(0^{\circ} \mathrm{C}\right)$. However, this is irrelevant for our study as we only use standardized pressure anomalies and pressure tendency. We focus on the sub-period 1799-1821, which can be considered internally homogeneous at least with respect to temperature (the homogenization of the full record is ongoing). There were no reported changes in station operation during that time. Measurements were made in the old botanical garden, situated on the Bastion St-Léger in the southwest of Geneva (Fig. 1). The old botanical garden had an effective area of $1800 \mathrm{~m}^{2}$ (Sigrist and Bungener, 2008) and hence the influence of surrounding buildings can be assumed small (Pictet, 1822). Before 1799 observations were made in Genthod, after 1822 (until 1825) the observation site was situated 
at the southeastern edge of the town. In 1826 it was relocated to the new botanical garden, on the northern shore of Lake Geneva (Schuepp, 1961).

During the period 1799-1821, Marc-Auguste Pictet was responsible for collecting and publishing the observational data. There are twice daily measurements of air temperature and pressure and twice daily observations of cloud cover, wind direction and (sometimes) speed. One observation was performed at sunrise (most likely local astronomical sunrise) with the aim of capturing the minimum temperature and one at 14:00 LT, which is close to the maximum. Because anomalies from the seasonal cycle are computed later on, the effects of systematic errors related to the time of observation are small. In addition to the twice daily reports, daily precipitation measurements are also reported. Of course, twice daily observations cannot capture a complete diurnal cycle, in contrast to, e.g. hourly observations. According to our information, there were no changes in instruments, reporting, and location during the period 1799-1821. However, notes in the station history revealed a trend inhomogeneity in this period which was corrected. Available calibration information indicated a drift in temperature, which is a known error that is caused by the chemical composition of the glass and has been studied in detail for the case of Hohenpeißenberg in Germany (see Winkler, 2009, and references therein). As the instrument in Geneva was of the same type as that used at Hohenpeißenberg and because the reported shift in the calibration $\left(0.6^{\circ} \mathrm{C}\right)$ also was very similar, we corrected it in the same way as Winkler (2009) by decreasing temperature by $0.1^{\circ} \mathrm{C}$ per year (from 1796-1801). From 1802 onwards we subtracted $0.6^{\circ} \mathrm{C}$. The instrument type used was a mercury thermometer with an isolated bulb, divided in 80 parts in unit degree Réaumur (Pictet, 1822).

Cloud cover observations were recorded qualitatively and noted verbally in a semi-standardized terminology. In a stepwise procedure, we categorized the cloud observations into six cloudiness groups, from clear sky to fully covered. For our analysis, we isolated days on which both the morning and noon observations could clearly be identified as either cloud free or fully covered, respectively. By analyzing the distribution of the cloudiness classes over time, we clearly found the cloud cover series to be inhomogeneous. Unreasonable cloud cover distributions and year-to-year variations appeared in the entire period 1799-1811 (which is partly also reflected in the terminology used). However, the period 1812-1821 was found to be more homogeneous and relatively reliable. Therefore, any further analysis involving cloud cover used only this (shorter) period.

\subsection{Analysis methods}

The period 1799-1821 was chosen as a base period. From this period we removed the volcanically perturbed years, namely the years 1815 to 1817 (which are perturbed by the eruption of Tambora in April 1815, Bradley and Jones, 1995) and the years 1809 to 1811 (unknown eruption in 1809, ColeDai et al., 2009). The remaining 16 years were used as a reference against which we could compare the YWS 1816. The focus in this paper is on the summer of 1816, although we also analyzed the summer of 1815 and the winters of 1815/16 and 1816/17 (L. Breda, unpublished master thesis).

First, temperature values were analyzed and compared to the reference because analyzing the occurrences of frost or other environmentally relevant indicators requires an absolute scale rather than anomalies. In a second step, a mean annual cycle for temperature was formed from the reference period by fitting a seasonal cycle consisting of the first two harmonics. We then subtracted this annual cycle from both the reference period and the YWS period in order to study anomalies. Precipitation was analyzed in the form of absolute values (not anomalies) because of its skewed and bounded distribution function and because the seasonal cycle is not well defined. In addition, statistics of precipitation frequency (number of days with $>0.1 \mathrm{~mm}$ ) and 24-h precipitation intensity (i.e. the amount of precipitation on days with precipitation $>0.1 \mathrm{~mm}$ ) were analyzed. For temperature anomalies and 24-h precipitation intensity, we estimated probability density functions in order to address the frequencies of weather extremes. Also, we assessed the dependence of temperature anomalies upon cloud cover. Note that due to homogeneity reasons (see Sect. 2), all analyses involving cloud cover used a reduced base period 1812-1821 (without the volcanically perturbed years 1815-1817).

Finally, in order to further analyze the mechanisms, we performed a simple weather type classification for summer based on wind direction, pressure, and pressure tendency in order to address the effects of changing frequencies of weather types and changes within weather types. The weather types were defined based on all summers in the reference period. Then the same criteria were applied to the summer of 1816 . By retaining only the weather type information for 1816, randomly sampling from the corresponding weather types during the reference period, and then comparing back with the observed anomaly, we estimate the contribution of changes in weather types to the anomalies in temperature, precipitation, or cloud cover. A Monte Carlo approach $(n=10000)$ was applied to obtain a measure of variability associated with the sampling, assuming temporal independence of the weather types from one day to the next. Although this assumption is certainly not valid, the effect on the result is considered small as other sampling strategies (e.g. distinguishing 1st and 2nd days in a sequence or sampling 2-day periods) gave similar results. 

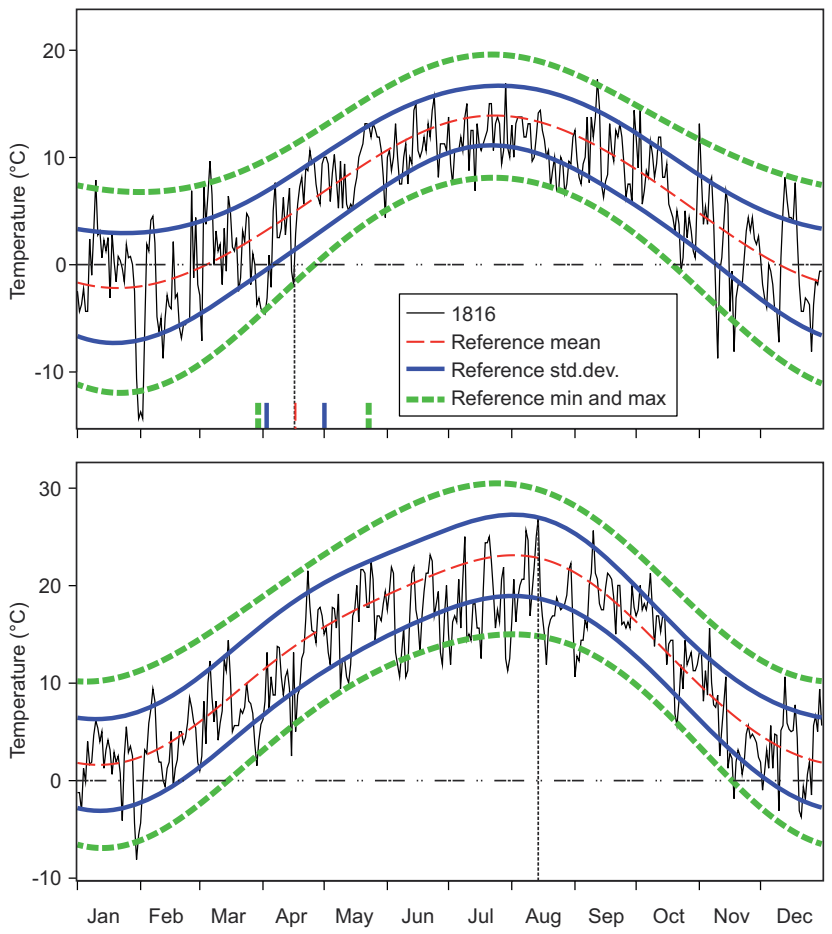

Fig. 2. Time series of daily values of temperature at sunrise (top panel) and 14:00 LT (bottom panel) in the year 1816 (thin black solid line) as well as for the average of the reference period (red dashed line). The blue (solid bold) lines denote \pm 1 standard deviation from the mean; the green (dashed bold) lines give the minima and maxima for the reference period. Note that all annual cycles from the reference period were obtained from the statistics for each calendar day. They were then smoothed by fitting the first two harmonics of the annual cycle. The black dotted vertical line in the upper panel indicates the last day of morning temperatures in spring below $0{ }^{\circ} \mathrm{C}$ in 1816 . Ticks on the $\mathrm{x}$-axis indicate the mean last dayof-year with morning temperatures below $0{ }^{\circ} \mathrm{C}$ in the reference period (red dashed tick), \pm 1 standard deviation (blue solid bold ticks), and the earliest and latest date with negative spring temperatures in the morning (green dashed bold ticks). The black dotted vertical line in the lower panel indicates the date of the annual maximum temperature in 1816.

\section{Results and discussion}

\subsection{Morning and afternoon temperature and frequency distributions}

Daily temperatures of the years 1816 are shown in Fig. 2 together with the mean annual cycle from the reference period as well as the corresponding annual cycle of minima and maxima. The last negative spring temperature in 1816 was observed at sunrise on 16 April. This corresponds almost exactly to the mean date of the last negative spring temperature in the reference period. The annual maximum temperature in 1816 was $26.9^{\circ} \mathrm{C}$ (observed on the afternoon of 14 August). Although this is a low value for an annual maximum, one even lower value was observed in the reference period.

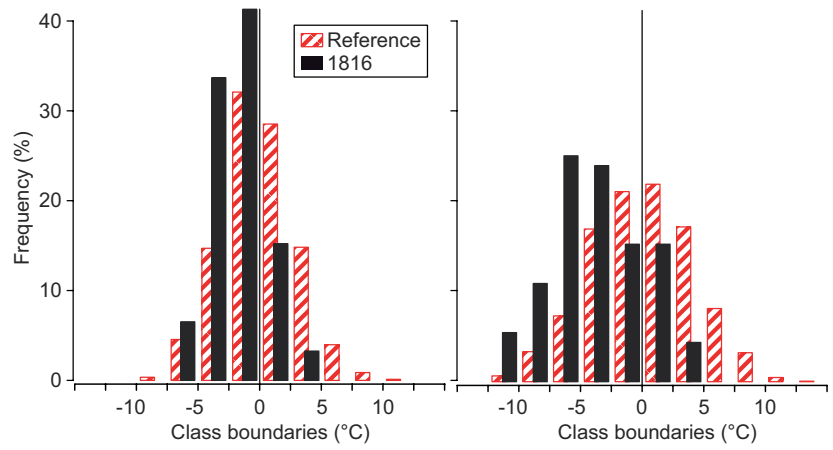

Fig. 3. Histograms showing the frequencies of occurrence (in percent) of temperature anomalies at sunrise (left panel) or 14:00 LT (right panel) in the summer months (June to August) of 1816 (black) and in the reference period (red patterned).

Both the early morning temperatures and afternoon temperatures were clearly and consistently below the reference mean in summer 1816. However, the afternoon temperatures were more anomalous than the early morning temperatures. This appears more clearly in Fig. 3, which shows histograms of the anomalies with respect to the reference period for the reference period (red) and the YWS (black) for the sunrise observation (left panel) and the 14:00 LT observation (right panel) for the summer period (June-August). The sunrise temperature was, on average, about $1.8^{\circ} \mathrm{C}$ cooler than the reference. Interestingly, the distribution is quite different. Contrary to what one might expect, negative extremes were not more frequent in 1816 than in the reference, but positive extremes were much less frequent in 1816 . The distribution is significantly narrower for 1816 than for the reference period. In the early afternoon, the difference in the mean was much larger and amounts to about $3.8^{\circ} \mathrm{C}$ cooling for 1816 relative to the reference period. In this case, the entire distribution is shifted: cold extremes were more frequent, warm extremes less frequent. From this analysis we conclude that the YWS was mainly an afternoon phenomenon.

\subsection{Frequency of cloud-free days and temperature anomalies}

Clouds might explain the different effect found in the sunrise and the 14:00 LT temperature. Cloud cover is expected to lead to an increase of the downwelling longwave radiation during the nights and to a decrease of the incoming shortwave radiation during the day. If nothing else changes, cloud cover would thus lead to warmer conditions at sunrise and colder conditions at 14:00 LT. This is observed in the (short) reference period (Table 1), where overcast nights were about $2{ }^{\circ} \mathrm{C}$ warmer than clear nights, and 14:00 LT temperature were about $6^{\circ} \mathrm{C}$ cooler, leading to a $8^{\circ} \mathrm{C}$ change in the difference between 4:00 LT and sunrise (which for simplicity we address as diurnal temperature range or DTR). 
Table 1. Effect of clouds on temperature. Averaged summertime (June-August) temperature anomalies $\left({ }^{\circ} \mathrm{C}\right)$ at sunrise and at 14:00 LT as well as their difference (diurnal temperature range, DTR) for days with clear sky (both sunrise and 14:00 LT) or fully overcast days (both sunrise and 14:00 LT) during a short reference period (1812-1814 and 1818-1821, i.e. the period with relatively reliable cloud observations) and in summer 1816. Row 5 shows the average temperature anomaly for the sum of overcast and clear days for 1816 assuming the mean values from the short reference in the first two rows and the number of fully overcast days (21) and fully clear days (15) from 1816. Row 6 is the same but using the mean values from the year 1816 itself. The lowest row shows the difference between the two. All temperature anomalies are with respect to the long reference period.

\begin{tabular}{llcrr}
\hline period & sky & sunrise & $14: 00 \mathrm{LT}$ & DTR \\
\hline short reference & overcast & 0.22 & -5.06 & -5.28 \\
short reference & clear & -1.77 & 1.04 & 2.81 \\
1816 & overcast & -0.92 & -6.96 & -6.05 \\
1816 & clear & -3.40 & -1.47 & 1.93 \\
1816 estimated & overcast + clear & -0.61 & -2.52 & -1.91 \\
from short & & & & \\
reference & & & & \\
1816 observed & overcast + clear & -1.95 & -4.67 & -2.72 \\
difference & overcast + clear & -1.34 & -2.16 & -0.82 \\
\hline
\end{tabular}

In fact, the summer of 1816 was anomalously cloudy. Not a single cloud-free day was observed in June 1816 and only 15 in the whole summer. This is much less than in the (short) reference period 1812-1821 (22 days). Conversely, the number of fully covered days was much larger in summer 1816 (21 days) than in the reference period (11 days).

Similar as in the reference period, overcast days in summer 1816 were ca. $5.5^{\circ} \mathrm{C}$ colder during the day and $2.5^{\circ} \mathrm{C}$ warmer during the night compared to clear days (Table 1), again resulting in an $8^{\circ} \mathrm{C}$ effect on DTR. However, in summer 1816 all temperature anomalies were much more negative compared to the short reference period. Fully covered summer days in 1816 were $1.1^{\circ} \mathrm{C}$ and $1.9^{\circ} \mathrm{C}$ colder than the reference for sunrise and 14:00 LT, respectively. Clear summer days were even $1.6^{\circ} \mathrm{C}$ and $2.5^{\circ} \mathrm{C}$ colder than in the reference period, for sunrise and 14:00 LT, respectively.

Can the temperature anomalies be explained by cloud cover alone? Table 1 (row 5) shows estimated average temperature anomalies for summer 1816 for sunrise and 14:00 LT (for cloudy plus clear days) assuming mean values for the corresponding categories in the short reference period. These numbers can then be compared to observed anomalies (for cloudy plus clear days) in 1816. For the 14:00 LT value, the estimated anomaly is $-2.16^{\circ} \mathrm{C}$ compared to an observed $-4.67^{\circ} \mathrm{C}$. Hence, about $50 \%$ of the afternoon summer temperature anomalies in 1816 can be explained by a simple cloud metric. Note, however, that this

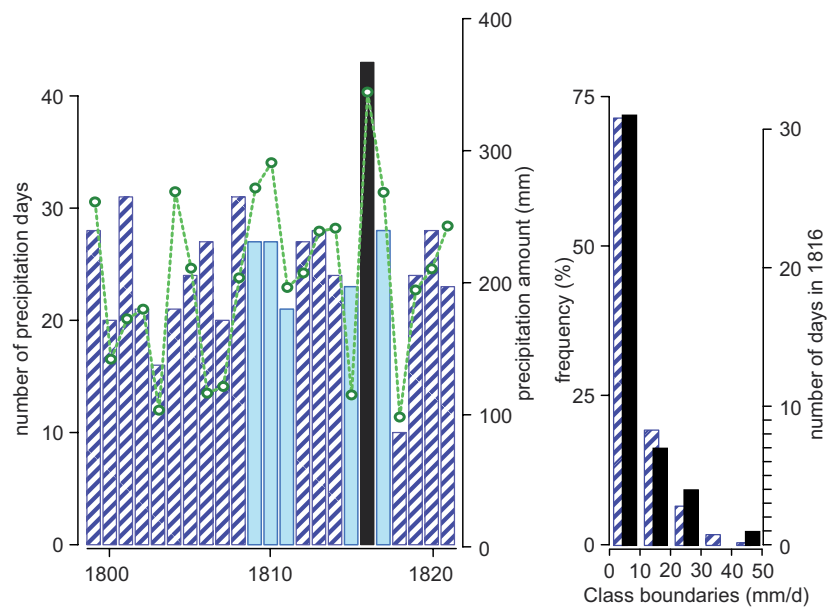

Fig. 4. Left panel: precipitation sums (green line, right scale) and number of rainy days (bars, left scale) in summer (June to August) from 1799-1821. The years that were excluded from the reference period are shown in light blue, 1816 in black. Right panel: histogram showing the frequency of occurrence (left scale: percent, right scale: number of days for 1816) of precipitation amounts in the summer months (June to August) of 1816 (black) and in the reference period (blue patterned). Note that precipitation amounts $<0.1 \mathrm{~mm}$ were excluded.

only addresses cloud-free and overcast conditions and that the reference period is shorter.

\subsection{Precipitation sum, frequency and intensity}

The total amount of rainfall was as much as $80 \%$ higher in summer 1816 compared to the reference period. Partitioning the precipitation sum into frequency and intensity (Fig. 4) reveals that this can be fully explained by an increase in the frequency of days with $>0.1 \mathrm{~mm}$ of precipitation of $80 \%$.

The mean rainfall intensity $(8 \mathrm{~mm}$ per day with $>0.1 \mathrm{~mm}$ precipitation) was the same in summer 1816 than for the average summer of the reference period (note that within the reference period, average summer precipitation intensities vary between 4 and $12 \mathrm{~mm} \mathrm{~d}^{-1}$, hence there is a considerable variation). Not only did the mean intensity not change, but we also find no evidence for changes in the distribution of precipitation intensities (Fig. 4, right panel). A $\chi^{2}$-test ( 4 classes with theoretical frequencies $>5$ ) yields a p-value of 0.96 . The highest daily precipitation amount in summer 1816 was $47.5 \mathrm{~mm}$, which is slightly higher than the maximum in the reference period $(43 \mathrm{~mm})$, but even higher values occurred in the two excluded years 1810 and 1811. The second highest amount (among 43 rainy days) was $27.2 \mathrm{~mm}$. This rainfall amount corresponds to the 96-percentile of the reference period, i.e. an excellent match. The fact that extreme precipitation events were not more frequent in 1816 than in "normal" summers contradicts to some extent the contemporary Swiss newspaper reports, which often speak about torrential rain falls and thunderstorms (see Bodenmann 
et al., 2011, although the reports cited therein do not specifically refer to the region of Geneva).

On the contrary to the wet summer 1816 , a notably dry summer appears in 1818 (Fig. 4). Both the total annual precipitation sum and also the number of precipitation days were the lowest within the whole period 1799-1821. Van der Schrier et al. (2007) use the self-calibrated Palmer Drought Severity Index (Wells et al., 2004) to identify wet and dry seasons over the Alps. Negative index values (dry conditions) within a prolonged period of positive values (18161825; wet conditions) for the NW-sector of the Greater Alpine region (including Geneva) for summer 1818 confirm our results. Furthermore, reconstructed SLP anomalies from Luterbacher et al. (2002) for summer 1818 show, in large contrast to the summer 1816, positive SLP anomalies (with the center west of the northern British Isles) covering almost all Europe (Trigo et al., 2009).

\subsection{Frequency of weather types}

For the 14:00 LT observation, we addressed the role of the mesoscale circulation by defining weather types and analyzing whether those types that typically are cold and rainy were more frequent in 1816 than in other years. Ideally, the classification should be chosen such that the classes that can be interpreted synoptically and distinguished from each other (i.e. large distance between classes in terms of mean temperature anomalies and precipitation) and at the same time have a small variability of these variables within each class. For forming classes, we confined ourselves to air pressure and wind direction because they define the atmospheric circulation most directly. Cloud cover is seen as a dependent variable and hence was not used to define weather types, especially since the time series is not homogeneous.

Wind occurrences provided a classification of wind direction into nine classes (calm, N, NE, W, SE, S, SW, W, NW). For pressure we used both the actual values as well as the tendency over the past $24 \mathrm{~h}$ to separate days into high, low, rising, falling, and stationary pressure (see below). The large annual variation in pressure variations made it necessary to base the classification on standardized anomalies, where annual cycles of both the mean and the standard deviation (s.d.) were computed as the first two harmonics of the corresponding data for each day-of-year from the reference period. Plotting the standardized data revealed an asymmetric distribution for pressure, but not for the pressure tendency. Hence, we considered non-symmetric thresholds in the case of pressure.

Cases with very low pressure or with very fast rising or falling pressure are often associated with the passage of a cold front. These cases show distinct temperature and precipitation anomalies. We used thresholds of \pm 2.5 s.d. for the pressure tendency and a threshold of $-2.5 \mathrm{~s}$.d. for pressure. All days that crossed one of the three thresholds were considered as frontal passages. The other days were separated into

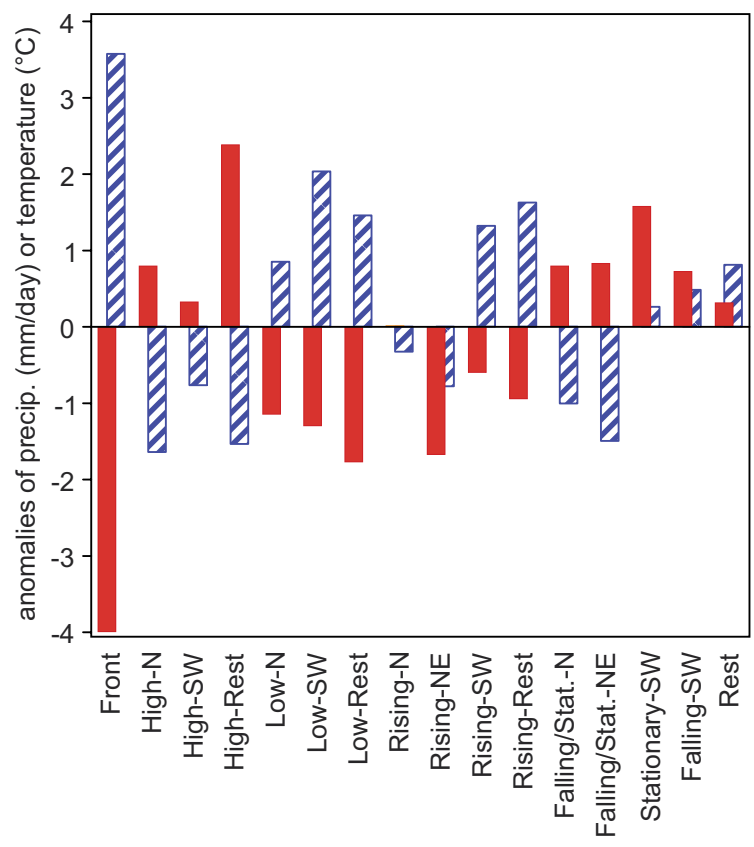

Fig. 5. Temperature anomalies (red) and precipitation (blue patterned) averaged for each weather type for the summer months (June to August) in the reference period. Note that for visualization purposes, precipitation is plotted as anomalies from the seasonal mean whereas the sampling operates with absolute values.

categories low, medium, or high pressure using the thresholds -1 and +0.75 s.d., respectively. The category medium pressure was further subdivided into rising, stationary, and falling pressure using the thresholds \pm 0.2 s.d. This results in a clearly defined and small (41 cases) class representing vigorous frontal passages as well as five large classes.

Each of these five classes could be subdivided into nine subclasses according to wind direction. However, this would result in a large number of classes, some of which represent very similar situations. We therefore combined subclasses according to the following rules: no class can have less than 30 members; classes to be combined must be neighboring (e.g. NW and W wind direction); and if several options were possible, the one that produced the smallest withinclass standard deviation for temperature was chosen. Due to orographic wind channeling (see Fig. 1), SW and NW winds prevailed in all 5 pressure classes. This allows for some synoptic interpretation. For instance, high pressure with SW winds can occur with W or NW gradient wind (and correspondingly, temperatures are lower than for high pressure situation with other wind directions).

The resulting classification for the reference period is shown in Table 2. Figure 5 shows the corresponding anomalies of temperature and precipitation in the reference period. The final classification had 16 classes, with sizes between 36 ("low pressure, rest") and 222 ("high pressure, northerly wind"). Mean temperature anomalies for the classes ranged 
Table 2. Weather type classification. Note that days classified as "fronts" could theoretically also fit in other categories, but were attributed to "front" (in practice this occurred only rarely). The fifth column indicates whether significant $(p<0.05)$ differences were found within this weather type between 1816 and the reference period according to a Wilcoxon test ( $y=$ yes, $n=$ no, $-=$ not enough cases). The sixth column indicates mean absolute frequencies of a weather type in the reference period for an average summer, JJA (annual averages). The last column indicates absolute frequencies of a weather type for summer 1816, JJA, in brackets: frequencies for the entire year 1816.

\begin{tabular}{|c|c|c|c|c|c|c|}
\hline \multirow[t]{2}{*}{ Class } & \multirow[t]{2}{*}{$p$} & \multirow[t]{2}{*}{$\mathrm{d} p / \mathrm{d} t$} & \multirow[t]{2}{*}{ wind } & \multirow[t]{2}{*}{ Sig. } & \multicolumn{2}{|c|}{ abs. freq. in JJA (year) } \\
\hline & & & & & Ref. & 1816 \\
\hline Front & $x<-2.5$ or: & $x<-2.5$ or $x>2.5$ & & $\mathrm{y}$ & $2(7)$ & $7(12)$ \\
\hline High pressure, northerly wind & $x>0.75$ & & $\mathrm{NW}, \mathrm{N}, \mathrm{NE}$ & - & $13(55)$ & $1(20)$ \\
\hline High pressure, southwesterly wind & $x>0.75$ & & SW & - & $3(17)$ & $0(12)$ \\
\hline High pressure, rest & $x>0.75$ & & Rest & - & $3(15)$ & $0(7)$ \\
\hline Low pressure, northerly wind & $-2.5<x<-1$ & & $\mathrm{NW}, \mathrm{N}, \mathrm{NE}$ & $\mathrm{y}$ & $4(17)$ & $8(22)$ \\
\hline Low pressure, southwesterly wind & $-2.5<x<-1$ & & SW & $\mathrm{y}$ & $7(29)$ & $31(62)$ \\
\hline Low pressure, rest & $-2.5<x<-1$ & & Rest & - & $2(9)$ & $0(3)$ \\
\hline Rising pressure, northerly wind & $-1<x<0.75$ & $x>0.2$ & $\mathrm{~N}$ & - & $4(11)$ & $0(4)$ \\
\hline Rising pressure, northeasterly wind & $-1<x<0.75$ & $x>0.2$ & $\mathrm{NE}$ & $\mathrm{n}$ & $6(23)$ & $14(41)$ \\
\hline Rising pressure, southwesterly wind & $-1<x<0.75$ & $x>0.2$ & SW & $\mathrm{y}$ & $6(26)$ & $8(30)$ \\
\hline Rising pressure, rest & $-1<x<0.75$ & $x>0.2$ & Rest & - & $3(13)$ & $4(15)$ \\
\hline Falling or stationary pressure, northerly wind & $-1<x<0.75$ & $x<0.2$ & $\mathrm{~N}$ & - & $7(18)$ & $0(9)$ \\
\hline Falling or stationary pressure, northeasterly wind & $-1<x<0.75$ & $x<0.2$ & $\mathrm{NE}$ & $\mathrm{y}$ & $8(37)$ & $14(54)$ \\
\hline Stationary pressure, southwesterly wind & $-1<x<0.75$ & $-0.2<x<0.2$ & SW & - & $4(21)$ & $2(25)$ \\
\hline Falling pressure, southwesterly wind & $-1<x<0.75$ & $x<-0.2$ & SW & - & $9(34)$ & $2(35)$ \\
\hline Falling or stationary pressure, rest & $-1<x<0.75$ & $x<0.2$ & E, SE, S, W, NW, calm & - & $8(31)$ & $1(15)$ \\
\hline
\end{tabular}

from $-4.0^{\circ} \mathrm{C}$ ("front") to $+2.4{ }^{\circ} \mathrm{C}$ ("high pressure, rest"). Precipitation anomalies range from $+3.4 \mathrm{~mm} \mathrm{~d}^{-1}$ ("front") to $-1.8 \mathrm{~mm} \mathrm{~d}^{-1}$ ("high pressure, northerly wind").

After the classification scheme was accepted, it was applied to the summer of 1816 and to the contemporary period 1981-2010. A comparison of the obtained distributions of weather types in the reference and the period 19812010 serves as a measure of usefulness of the classification methodology. Figure 6 shows the distribution of weather types in summer 1816, in the reference period, and in the period 1981-2010 as a histogram. In general, markedly similar patterns are obtained in the periods 1799-1821 and 19812010. However, the class "Rest" is more frequent in the period 1981-2010. We therefore claim that our classification methodology and the thereof derived weather types can be readily used for comparing local circulation patterns in 1816 to the reference period. The main differences between 1816 and the reference period are the almost complete absence of the three high pressure situations in summer 1816 (with only one case), which in the reference period together account for $21 \%$ of the days (corresponding to 20 days in an average summer). In contrast, the class "low pressure, southwesterly winds" was 3.5 times as frequent in 1816 as in the reference period. Hence, the "year without summer" of 1816 in Geneva can be explained by frequency shifts of only few weather types: an absence of high pressure situation and a tripling of low-pressure situations.

Seasonal SLP reconstructions from Küttel et al. (2010) are consistent with this result. Figure 7 shows the corresponding anomalies for June-to-August with respect to the reference.

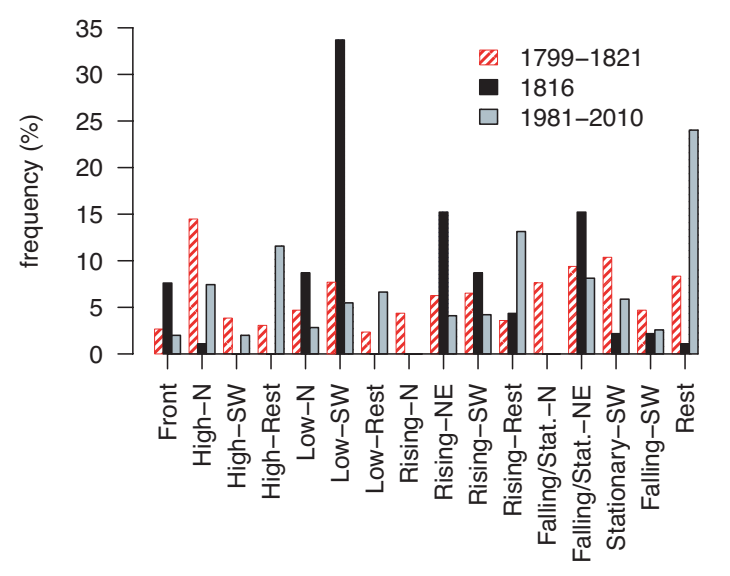

Fig. 6. Histogram showing the frequency of occurrence (percent) of weather types in the summer months (June to August) of 1816 (black), in the reference period (red patterned), and in the period 1981-2010 (light grey).

A very large center with negative SLP anomalies appears over northern France. Geneva (dot in Fig. 7) was to the south of this center. This is expected from an increase in low pressure situations and in situations with westerly geostrophic flow (which in Geneva could be channeled to southwesterly wind). In addition Fig. $7 \mathrm{~b}$ shows the reconstructed absolute SLP values for June-to-August.

Casty et al. (2005b) investigated large scale climate regimes over the North Atlantic/European sector since 1766. They show that the period 1805-1825, which overlaps to 


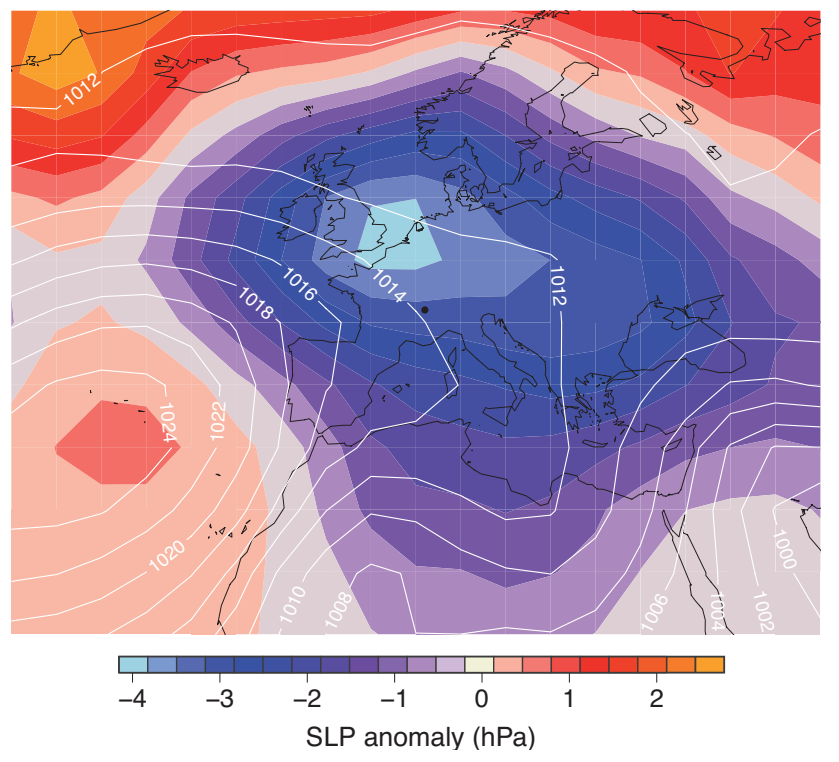

Fig. 7. SLP anomaly for summer (June to August) 1816 with respect to the reference period and absolute SLP values (white contours). The dot marks the location of Geneva.

a great extent the reference period, is characterized by an anomalously westerly flow regime. However, the reconstructed parameters are confined to winter (December-toFebruary). According to Casty et al. (2005a) analysis of Alpine temperatures, the cold summer 1816 was the coldest of a series of below-average summers, which followed a period with generally warm summers between 1780 and 1810 (the warmest being 1807). While winter climate anomaly patterns can be analyzed in the framework of large scale circulation variability, this is more difficult for the summer seasons both because of weaker relations between climate and circulation indices and the lower reconstruction skill of circulation indices. In fact, the anomaly pattern of SLP (Fig. 7) does not project strongly onto the NAO pattern but rather resembles the East Atlantic pattern. Whether this pattern is affected by global volcanic forcing remains to be explored. As the winter 1815/1816 was likely an El Niño winter, remote effects from the tropical Pacific could be considered. There is a tendency for an excitement of such a pattern accompanied by increased precipitation over central Europe in springs following El Niño winters, which was also found in climate reconstructions (Brönnimann et al., 2007). However, the relation between El Niño and European climate is weak.

\subsection{Contribution of weather types to temperature anomalies}

How much of the afternoon cooling in summer 1816 can be reproduced from sampling corresponding weather types in the reference period? Figure 8 shows estimated temperatures anomalies and precipitation sums (histograms of
10000 repetitions) together with the actual values for summer 1816 as well as the mean values for summers in the reference period. While for temperature, the distribution is symmetric, it is slightly asymmetric for precipitation, indicating that the uncertainty is higher towards the high precipitation sums.

Out of 10000 estimated 14:00 LT seasonal mean temperature anomalies, $99 \%$ of the values are below zero (and hence below the reference period). The mean value is $-1.00^{\circ} \mathrm{C}$. Hence, there is no doubt that unusual weather types affected temperature in Geneva. However, the expected contribution of the weather types to the actually observed anomaly is only about one fourth. In fact, the actually observed anomaly is well below the range of the Monte Carlo simulations. One might be tempted to attribute the remainder to direct volcanic effects. However, there might also be other effects that are not captured by the classification. The weather types capture an (unknown) mesoscale and not necessarily large-scale or small-scale effects.

To test this, we applied the same procedure (but now sampling only the mean values of a class) to all years in the reference period (during which no specific forcing was operating) and also to the summers of 1809, 1810, 1811, 1815, and 1817. Results are shown in Fig. 9. For temperature, there is a clear correlation between the artificial and the observed temperature anomalies that reaches 0.72 when including all years. This indicates that the not-captured part of the circulation effect on temperature correlates well with the captured part. In other words, about $50 \%$ (in terms of variance) or $25 \%$ (in terms of magnitude) of summer temperature anomalies can be explained by changing frequencies of weather types. The summer of 1816 lies close to a regression line drawn through the data points in the reference period (not shown). From this analysis we conclude that the temperature anomaly in Geneva in 1816 is not inconsistent with only a change in atmospheric circulation, although the uncertainty of the analysis is larger, leaving room for substantial non circulation-related cooling. At the same time, it is important to note that the temperature anomaly predicted only from the weather types is more than twice as negative as in any other case in the reference period.

We also analyzed whether or not there are significant differences between temperature anomalies in 1816 and the reference period within the same weather type. We performed the Wilcoxon rank sum test for all classes for which at least seven days were available in 1816. With one exception ("Rising pressure, northeasterly wind"), all classes exhibited a significantly lower mean temperature in 1816 compared to the reference period (Table 2). This analysis again suggests that not all of the cooling can be captured by the weather type frequencies, which can be due to an inadequate classification or a "missing" mechanism. 

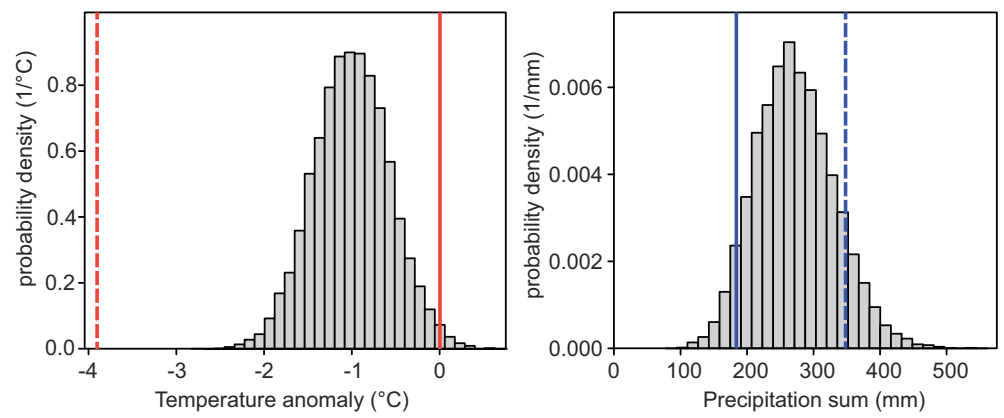

Fig. 8. Histogram showing 10000 artificial temperature anomaly averages (left panel) and precipitation sums (right panel) for the summer of 1816 based on weather types for 1816 and sampling from these weather types in the reference period. The dotted and solid lines denote the observed values for the year 1816 and the reference period, respectively.
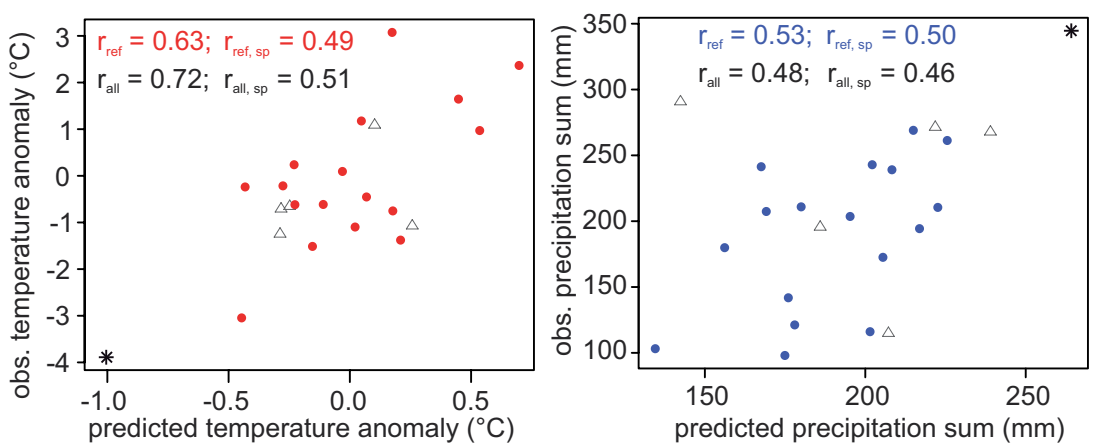

Fig. 9. Scatter plot showing the observed temperature anomalies (left panel) and precipitation sums (right panel) as a function of their predicted values based only on the weather types information. The years in the reference period are indicated in red and blue (points), for temperature and precipitation, respectively, the years that were excluded from the reference period are shown in grey (triangles), 1816 in black (stars). Correlation $(r)$ and non parametric Spearman correlation $\left(r_{\mathrm{sp}}\right)$ coefficients are shown for only the reference period (subscript ref, red number) and all years (subscript all, black number).

\subsection{Contribution of weather types to precipitation anomalies}

The same analyses were performed with respect to precipitation. Of the 10000 estimated precipitation sums for summer 1816 (Fig. 8), $94 \%$ are higher than the reference period mean. Hence, there are indications that unusual weather types contributed to the precipitation surplus in Geneva in summer 1816, but the uncertainty is much larger than in the case of temperature. The uncertainty range includes the observed value.

Applying the procedure to all years (Fig. 9), we also find correlations between observed and predicted precipitation, but compared to the analysis for temperature correlations these are much lower and only significant for the reference period (not for the full period). Only $25 \%$ of the interannual precipitation variability can be explained by changed weather types. The summer of 1816 falls within the relation found in the reference period and hence is not inconsistent with only a change in atmospheric circulation. However, as for temperature, it is important to note that the precipitation amount predicted for summer 1816 only from the weather types far exceeds any other value in the $1799-1821$ period. The Wilcoxon test for within-class differences revealed significant differences only for one class ("front"). Hence, we have no evidence to falsify the hypothesis that the precipitation anomalies are caused by atmospheric circulation.

\subsection{Contribution of weather types to cloud cover anomalies}

We used the same methodology, albeit with the shorter calibration period, to estimate the fraction of cloud-free days (not shown). This variable could be well reproduced from weather types (estimated for 1816: $19.3 \%$, observed: $16.3 \%$, reference period: $25.2 \%$ ). According to the Monte Carlo simulation, the estimated fraction deviates significantly $(p<0.01)$ from the reference but not from the observed value. 


\section{Discussion and conclusions}

We have digitized sub-daily meteorological data from the station Geneva in order to analyze the "Year Without Summer" of 1816. We chose a sub-period of the record which was found to be homogeneous after the correction of one (known) error. Comparing the YWS 1816 to the remainder of that period (1799-1821) reveals that the coldness of the summer 1816 was most prominent in the afternoon. The entire temperature distribution function was shifted by almost $4{ }^{\circ} \mathrm{C}$ towards lower values with no apparent change in variability. In contrast, early morning temperatures show a significant decrease in the variability, but no changes in negative extremes and a smaller change for the mean.

Possible causes for changes between 1816 and the reference period include direct radiative changes (due to volcanic aerosols or clouds), changes in the mesoscale circulation (e.g. the frequency of weather types), and changes in the large-scale climate system (e.g. a cooling of the oceans). The mechanisms are not independent and hence hardly separable. Although an attribution of the causes is not possible using only observational data, they still provide interesting insights which, if well characterized, can be used in model comparisons.

Analyzing cloud information suggests that an increase in cloud cover was mainly responsible for time-of-day characteristics of the temperature change. But what changed the clouds? A simple weather type classification (according to pressure, pressure tendency, and wind direction) well explains the changes in cloud cover. About one fourth of the deviation in the seasonal mean afternoon temperature can be explained by changes in weather type (i.e. the mesoscale circulation). Although this may seem a small fraction, it corresponds exactly to the expected fraction of explained variance for any anomalous year. Importantly, the amount of weather-type-related cooling was much larger than in other years and the within-type differences of afternoon temperature were significant in most cases. For precipitation, our analysis shows that the $80 \%$ increase in summer precipitation can be explained solely by a higher frequency of precipitation, while no change could be found in the 24-h intensity of precipitation (including the occurrence of extremes).

In all, the results show that the year without summer was not characterized by extreme weather (the tails of the distributions did not change much except for cold afternoons), but extreme climate (i.e. the statistics of weather types changed). The analysis shows that the local-to-regional circulation plays a dominant role in that all climatic anomalies are statistically consistent with only a change in circulation. Historical analyses show that in Switzerland, strong tropical volcanic eruptions are often followed by a "Year Without Summer" with very similar weather as in the summer of 1816 (Pfister, 1999, see also Fischer et al., 2007), suggesting a mechanism linking tropical volcanic forcing to persistent regional circulation and cloud cover anomalies over Western Europe in summer.

\section{Supplementary material related to this article is available online at: http://www.clim-past.net/8/325/2012/ cp-8-325-2012-supplement.zip.}

Acknowledgements. The project was supported by the Swiss National Science Foundation via the NCCR Climate project PALVAREX, by the cogito foundation, by the Department of Environmental Sciences, ETH Zurich and by the COST Action HOME. Data for this study were digitized within the framework of the cooperative DigiHom project of MeteoSwiss and ETH Zurich. We would like to thank Michael Begert, Christine Füllemann, and Mischa Croci-Maspoli (all MeteoSwiss) for providing metadata and helpful discussions. Thanks also to Stéphane Fischer (Musée d'Histoire des Sciences, Geneva) for information on historic instruments.

Edited by: P. Brohan

\section{References}

Alexander, L. V.: Global observed changes in daily climate extremes of temperature and precipitation, J. Geophys. Res., 111, D05109, doi:10.1029/2005JD006290, 2006.

Baron, W. R.: 1816 in perspective: the view from the Northeastern United States, in: The year without a summer?: world climate in 1816, edited by: Harrington, C. R., Canadian Museum of Nature, Ottawa, 124-144, 1992.

Bodenmann, T., Hirsch Hadorn, G., Brönnimann, S., Krüger, T., and Weissert, H.: Perceiving, understanding, and observing climatic changes: An historical case study of the "year without summer" 1816, Meteorol. Z., 20, 577-587, doi:10.1127/09412948/2011/0288, 2011

Bradley, R. and Jones, P. D.: Records of explosive volcanic eruptions over the last 500 years, in: Climate Since A.D. 1500, edited by: Bradley, R. S. and Jones, P. D., Routledge, London, 1995.

Brandsma, T. and Können, G. P.: Application of nearest neighbor resampling for homogenizing temperature records on a daily to sub-daily level, Int. J. Climatol., 26, 75-89, doi:10.1002/joc.1236, 2006.

Briffa, K. and Jones, P. D.: the climate of Europe during the 1810s with special reference to 1816 , in: The year without a summer? world climate in 1816, edited by: Harrington, C. R., Canadian Museum of Nature, Ottawa, 372-391, 1992.

Briffa, K., Jones, P. D., Schweingruber, F., and Osborn, T.: Influence of volcanic eruptions on Northern Hemisphere Summer temperature over the Past 600 Years, Nature, 393, 450-455, 1998.

Brönnimann, S., Xoplaki, E., Casty, C., Pauling, A., and Luterbacher, J.: ENSO influence on Europe during the last centuries, Clim. Dynam., 28, 181-197, doi:10.1007/s00382-006-0175-z, 2007.

Casty, C., Handorf, D., and Sempf, M.: Combined climate winter regimes over the North Atlantic/European sector 1766-2000, Geophys. Res. Lett., 32, 13, doi:10.1029/2005GL022431, 2005a. 
Casty, C., Wanner, H., Luterbacher, J., Esper, J., and Böhm, R.: Temperature and precipitation variability in the European Alps since 1500, Int. J. Climatol., 25, 1855-1880, doi:10.1002/joc. 1216, 2005b.

Chenoweth, M.: Two major volcanic cooling episodes derived from global marine air temperatures, Geophys. Res. Lett., 28, $2963-$ 2966, 2001.

Chenoweth, M.: Daily synoptic weather map analysis of the New England cold wave and snowstorms of 5 to 11 June 1816, in: Historical climate variability and impacts in North America, edited by: Dupigny-Giroux, L.-A. and Mock, C. J., Springer, Dordrecht, 2009.

Cole-Dai, J., Ferris, D., Lanciki, A., Savarino, J., Baroni, M., and Thiemens, M. H.: Cold decade (AD 18101819) caused by Tambora (1815) and another (1809) stratospheric volcanic eruption, Geophys. Res. Lett., 36, L22703, doi:10.1029/2009GL040882, 2009.

Fischer, E., Luterbacher, J., Zorita, E., Tett, S., Casty, C., and Wanner, H.: European climate response to tropical volcanic eruptions over the last half millennium, Geophys. Res. Lett., 34, L05707, doi:10.1029/2006GL027992, 2007.

Harrington, C. R.: The year without a summer?: world climate in 1816, Ottawa: Canadian Museum of Nature, 1992.

Hoyt, J.: The cold summer of 1816, Ann. Assoc. Am. Geogr., 48, 118-131, 1958.

Kington, J.: Weather patterns over Europe in 1816, in: The year without a summer?: world climate in 1816, edited by: Harrington, C. R., Canadian Museum of Nature, Ottawa, 358-371, 1992.

Küttel, M., Xoplaki, E., Gallego, D., Luterbacher, J., GarcíaHerrera, R., Allan, R., Barriendos, M., Jones, P. D., Wheeler, D., and Wanner, H.: The importance of ship log data: reconstructing North Atlantic, European and Mediterranean sea level pressure fields back to 1750, Clim. Dynam., 34, 1115-1128, 2010.

Lean, J., Beer, J., and Bradley, R.: Reconstruction of solar irradiance since 1610: Implications for climate change, Geophys. Res. Lett., 22, 3195-3198, 1995.

Luterbacher, J., Xoplaki, E., Dietrich, D., Rickli, R., Jacobeit, J., Beck, C., Gyalistras, D., Schmutz, C., and Wanner, H.: Reconstruction of sea-level pressure fields over the eastern North Atlantic and Europe back to 1500, Clim. Dynam., 18, 545-561, doi:10.1007/s00382-001-0196-6, 2002.

Luterbacher, J., Dietrich, D., Xoplaki, E., Grosjean, M., and Wanner, H.: European seasonal and annual temperature variability, trends and extremes since 1500 a.d., Science, 303, 1499-1503, 2004.

Mann, M., Bradley, R., and Hughes, M.: Global-scale temperature patterns and climate forcing over the past six centuries, Nature, 392, 779-787, 1998.

Oppenheimer, C.: Climatic, environmental and human consequences of the largest known historic eruption: Tambora volcano (Indonesia) 1815, Prog. Phys. Geog., 27, 230-259, 2003.

Pfister, C.: The Years without a Summer in Switzerland: 1628 and 1816, in: The year without a summer?: world climate in 1816 , edited by: Harrington, C. R., Canadian Museum of Nature, Ottawa, 416-417, 1992.
Pfister, C.: Wetternachhersage: 500 Jahre Klimavariationen und Naturkatastrophen (1496-1995), Paul Haupt, Bern, 1999.

Pictet, M. A.: Bibliothèque universelle des sciences, belles-lettres et arts Sciences et arts, Imprimerie de a bibliothèque universelle ed, Genève, 1822.

Piervitali, E., Conte, M., and Colacino, M.: Summer air temperature anomalies in europe during the century 1811-1910, Il Nuovo Cimento, C20, 195-208, 1997.

Robock, A.: Review of year without a summer? World climate in 1816, Climatic Change, 26, 105-108, 1994.

Robock, A.: Volcanic eruptions and climate, Rev. Geophys., 38, 191-219, 2000.

Schuepp, M.: Lufttemperatur, Beiheft zu den Annalen der SMZ, Fotorotar AG, Zürich, 1961

Self, S., Rampino, R. R., and Barbera, J. J.: The possible effects of large 19th and 20th century volcanic eruptions on zonal and hemispheric surface temperatures, J. Volcanol. Geoth.-Res., 11, 41-60, 1980.

Shindell, D., Schmidt, G., Mann, M., and Faluvegi, G.: Dynamic winter climate response to large tropical volcanic eruptions since 1600, J. Geophys. Res.-Atmos., 109, D05104, doi:10.1029/2003JD004151, 2004.

Sigrist, R. and Bungener, P.: The first botanical gardens in geneva (c. 1750-1830): private initiative leading science, St. Hist. Gard. Des. L., 28, 333-350, 2008.

Skeen, E. K.: The Year without a Summer: A Historical View, J. Early Republ., 1, 51-67, 1981.

Stendel, M., Mogensen, I., and Christensen, J.: Influence of various forcings on global climate in historical times using a coupled atmosphere-ocean general circulation model, Clim. Dynam., 26, $1-15,2005$.

Stommel, H. and Stommel, E.: Volcano Weather: The Story of 1816, The Year without a Summer, Seven Seas Press ed., Newport, Rhode Island, 1983.

Stothers, R.: The great Tambora eruption in 1815 and its aftermath, Science, 224, 1191-1198, 1984.

Stothers, R.: Volcanic dry fogs, climate cooling and plague pandemics in europe and the middle east, Climatic Change, 42, 713723, 1999.

Trigo, R. M., Vaquero, J. M., Alcoforado, M. J., Barriendos, M., Taborda, J., Garcia-Herera, R., and Luterbacher, J.: Iberia in 1816, the year without a summer, Int. J. Climatol., 29, 99-115, 2009.

van der Schrier, G., Efthymiadis, D., Briffa, K. R., and Jones, P. D.: European Alpine moisture variability for 1800-2003, Int. J. Climatol, 27, 415-427, doi:10.1002/joc.1411, 2007.

Wells, N., Goddard, S., and Hayes, M. J.: A self-calibrating Palmer Drought Severity Index, J. Climate, 17, 2335-2351, doi:10.1175/1520-0442(2004)017<2335:ASPDSI > 2.0.CO;2, 2004.

Winkler, P.: Revision and necessary correction of the long-term temperature series of Hohenpeissenberg, 1781-2006, Theor. Appl. Climatol., 98, 259-268, 2009. 